\title{
BMJ Open Suicide after cancer diagnosis in South Korea: a population-based cohort study
}

\author{
Young Choi (D) ,' Eun-Cheol Park (D) ${ }^{2}$
}

To cite: Choi Y, Park E-C. Suicide after cancer diagnosis in South Korea: a populationbased cohort study. BMJ Open 2021;11:e049358. doi:10.1136/ bmjopen-2021-049358

- Prepublication history and additional supplemental material for this paper are available online. To view these files, please visit the journal online (http://dx.doi.org/10.1136/ bmjopen-2021-049358).

Received 22 January 2021 Accepted 30 July 2021
Check for updates

(c) Author(s) (or their employer(s)) 2021. Re-use permitted under CC BY-NC. No commercial re-use. See rights and permissions. Published by BMJ.

${ }^{1}$ Department of Healthcare Management, Catholic University of Pusan, Busan, Republic of Korea

${ }^{2}$ Department of Preventive Medicine and Institute of Health Services Research, Yonsei University College of Medicine, Seoul, Republic of Korea

Correspondence to

Dr Eun-Cheol Park;

ecpark@yuhs.ac

\section{ABSTRACT}

Objective The present study aimed to determine whether the suicide risk increased after a cancer diagnosis.

Design Population-based cohort study.

Setting and participants This study incorporated the National Health Insurance Service-National Sample Cohort in South Korea. Of the 975348 subjects, 39027 with cancer and 936321 who were cancer free participated between 2005 and 2013.

Primary outcome measure Suicide.

Results A total of 110 suicides (82 men, 28 women) were identified among these 39027 subjects with cancer during a total of 127184 person-years; among the 936321 cancer-free subjects, 2163 suicides were reported during a total of 8222479 person-years. Cox proportional hazards models were used to compare all-cause and suicide mortalities after cancer diagnosis following adjustment for possible confounding covariates. After adjusting for factors related to suicide, we identified an elevated relative risk of suicide among patients with cancer (HR: 1.480, 95\% Cl: 1.209 to 1.812 ). Among men, the relative risk was substantially increased among patients with lip, oral cavity/pharyngeal, colon and rectal, pancreatic and lung cancers when compared with cancer-free subjects; whereas among women, the relative risk was substantially increased among patients with colon and rectal cancers. Conclusion Our study observed an increased risk of suicide among patients with cancer that varied according to the anatomical cancer site, even after accounting for clinical comorbidities and psychiatric illness. Our findings indicate a need for social support and suicide prevention strategies for patients with cancer.

\section{INTRODUCTION}

Suicide is considered a major public health challenge and is among the leading global causes of a loss of life years. ${ }^{1}$ Notably, South Korea has the highest suicide rate among member nations of the Organization for Economic Co-operation and Development. ${ }^{2}$ Suicide rates have continued to increase in South Korea throughout the past two decades with a peak in 2010 , leading to the current designation of suicide as the fourth leading cause of death nationwide. ${ }^{3}$

A cancer diagnosis is a stressful and lifethreatening event that causes considerable physical and psychological suffering. ${ }^{45}$ The associated distress might not only worsen the quality of life ${ }^{6}$ and accelerate disease
Strengths and limitations of this study

- The strengths of this study included the populationbased design and acquisition of data from the National Health Insurance Service-National Sample Cohort, which is representative of the entire Korean population.

- This study featured a robust follow-up resulting from the use of unique personal identification numbers for Korean residents, which were linked to the national mortality database.

- We were unable to examine the risk factors associated with specific cancer types because of the small number of suicides in each specific cancer group.

- We were unable to identify some potential risk factors known to have important influences on suicide among patients with cancer.

- The use of administrative claims data is associated with a reliance on International Classification of Diseases-10 codes to determine comorbidity could lead to misclassification consequent to miscoding behaviours.

progression, ${ }^{7}$ but may also promote noncancer mortality. 89 Patients with cancer, particularly, have a higher risk of suicide relative to that of the general population, and this risk may increase by up to twofold in many countries. ${ }^{10-16}$ A large body of evidence has identified many factors related to suicide among patients with cancer, including particular clinical characteristics, age at diagnosis, prognosis, stage, time since diagnosis, psychiatric health, and sociodemographic factors such as sex, race, and marital status. ${ }^{17}$ Previous studies also have found that the incidence of suicide is relatively high among patients with pancreatic, ${ }^{1018} 19$ lung, ${ }^{10} 12131920$ colon and rectal, ${ }^{1321}$ oral cavity/ pharyngeal, ${ }^{12} 1318$ laryngeal, ${ }^{13}$ stomach $^{12} 19$ and cervical cancer. ${ }^{21}$

Despite the accumulation of evidence in support of an association between cancer and suicide, several studies have calculated the standardised mortality ratios (SMRs) to compare the suicide rate between patients with cancer and the general population while only evaluating differences in sociodemographic and clinical characteristics. ${ }^{12} 1316$ 
Additionally, previous studies have been limited by a failure to adjust for underlying psychiatric conditions, ${ }^{10} 121316$ even though pre-existing psychiatric conditions might modify the impact of a cancer diagnosis on the risk of suicide ${ }^{22}$ particularly as cancer itself has been identified as a suicide risk factor when coupled with comorbidities such as psychiatric disease. Therefore, we investigated whether the suicide rate is higher among Korean patients with cancer than among the general population after controlling for underlying diseases including psychiatric disorders as well as sociodemographic and clinical characteristics. We further compared the risk of suicide according to the anatomical site of cancer with the risk observed in the general population.

\section{METHODS AND MATERIALS \\ Data sources}

As described in detail previously, ${ }^{23}$ data were acquired from the National Health Insurance Service-National Sample Cohort (NHIS-NSC) from 2002 to 2013 and included 1025340 representative subjects $(2.2 \%$ of the population) who were randomly stratified and selected based on age, sex, insurance type, income, residential region and individual total medical costs at 2002. As all Korean citizens are obligated to enrol in the single-payer, national health insurance and medical aid programme administered by the National Health Insurance Corporation, this sample cohort is representative of the general Korean population. The NHIS-NSC database includes information regarding patients' unique de-identification numbers, age, sex, insurance type, diagnosis according to the International Classification of Diseases (ICD-10), medical costs and prescribed drugs. In addition, these numbers are linked to mortality information from the Korean National Statistical Office (KNSO). By law, all causes of death must be reported to the KNSO within 1 month of occurrence. Details of the NHIS-NSC database have been provided in a previous report. ${ }^{24}$

\section{Study participants and follow-up}

Of the 1025340 subjects, we eliminated 17297 patients who had been diagnosed with cancer between 2002 and 2004, thus ensuring the selection of cancer-free subjects at baseline. We additionally eliminated 32695 subjects for whom information was missing due to a follow-up loss (death, emigration or disqualification from national health insurance) between 2002 and 2004. Overall, this study included 975348 subjects (online supplemental figure 1).

\section{Outcome and follow-up}

The outcome variables for this study were all-cause mortality and suicide (ICD-10 code X64-80). All subjects were observed from 1 January 2005 to follow-up loss, death (by suicide or any other cause) or 31 December 2013, whichever occurred first. For subjects who did not develop cancer, follow-up ended on the date of suicide, other death, emigration or 31 December 2013, whichever occurred first; accumulated person-time was defined as the unexposed person-time. For those who were diagnosed with cancer, the follow-up ended with the occurrence of suicide, other death, emigration out of Korea or 31 December 2013, whichever came first; accumulated person-time was defined as the exposed person-time. Participants diagnosed with cancer during the study period contributed unexposed person-time prior to the date of diagnosis (as recorded in the national health insurance data) and exposed person-time thereafter.

\section{Cancer diagnosis}

Cancer diagnoses were organised into 13 diagnostic groups: lip, oral cavity and pharynx (ICD-10 codes C00, C11, C12, C13, C14); stomach (C16); colon and rectum (C17, C18, C19, C20, C21); liver (C22); gallbladder and pancreas (C23, C24, C25); lung (C33, C34); breast (C50); gynaecological (cervix, uterus and ovary: C53, C54, C56); prostate (C61); testis and other male genital organs (C62); bladder (C67); thyroid (C73); and others (oesophagus: C15; larynx: C32; skin: C43, C44; kidney: C64, C65, C66, C68; brain and central nervous system: C70, C71, C72; Hodgkin's lymphoma: C81; non-Hodgkin's lymphoma: C82, C83, C84, C85, C96; leukaemia: C91, C92, C93, C94, C95).

\section{Covariates}

Sociodemographic and clinical risk factors for suicide were included in this study. Sociodemographic factors recorded on the date of entry into the study included sex, age ( $\leq 39,40-49,50-59,60-69$ and $\geq 70$ years), region (urban or rural) and household income (income quintiles Q1 (low) to Q5 (high)). We used the average monthly insurance premium as a proxy for household income. In Korea, individuals qualify for medical aid if their household income is less than $\$ 600$ per month; otherwise, they qualify for national health insurance. Individuals enrolled in the national health insurance programme were distributed between the 1st and 100th income percentiles, whereas those receiving medical aid were classified at the zero percentile. In this study, the following household income classification was used: Q1, $<20 \%$; Q2, 21\%-40\%; Q3, 41\%-60\%; Q4, 61\%-80\% and Q5, $>80 \%$. We also included the experience of at least one disability (according to the disabled person welfare law), including intellectual disability, brain lesion, deafness, physical disability, visual impairment, mental disorder, kidney disorder, language disorder, autism, heart disability, respiratory disorder, hepatopathy, facial disorders, having undergone ostomy and epilepsy.

Regarding clinical factors, patients' comorbidities were identified via review of their medical histories 12 months prior to study entry. Using the Charlson Comorbidity Index, we measured 17 comorbidities to control for the case mix. ${ }^{25}$ Additionally, underlying diagnoses related to psychiatric disorders included substance abuse (F10F19), schizophrenia disorder (F20-F29), bipolar disorder 


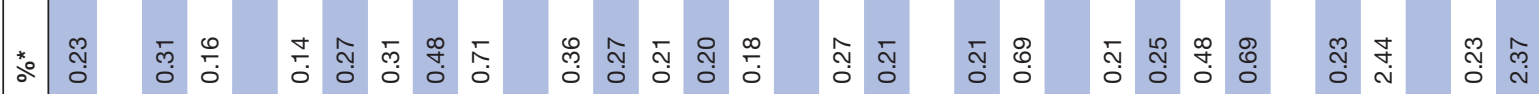
=

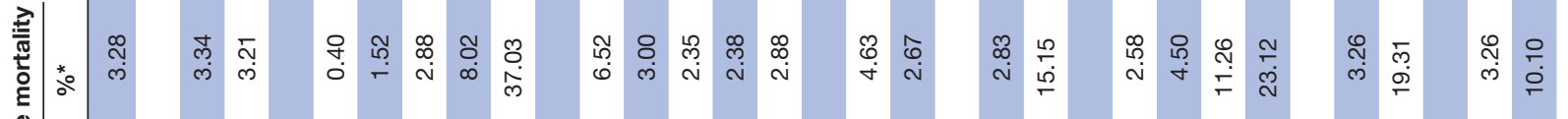

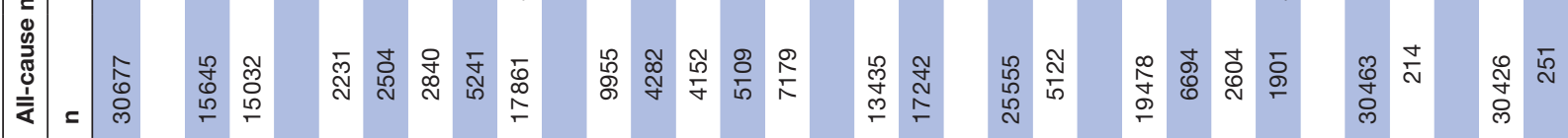

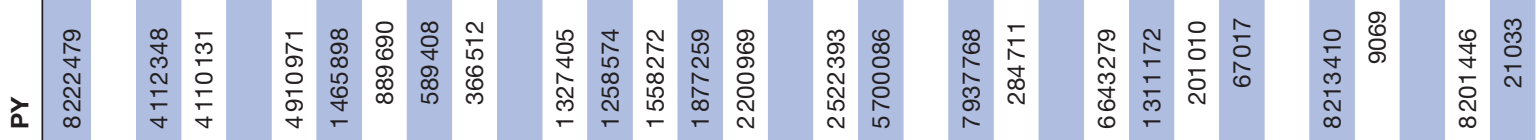

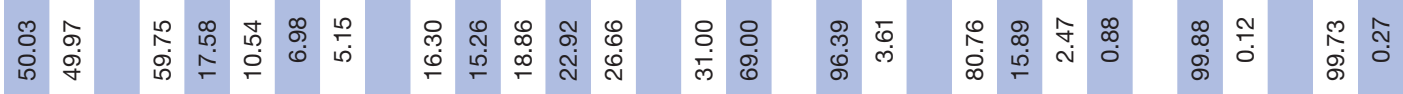

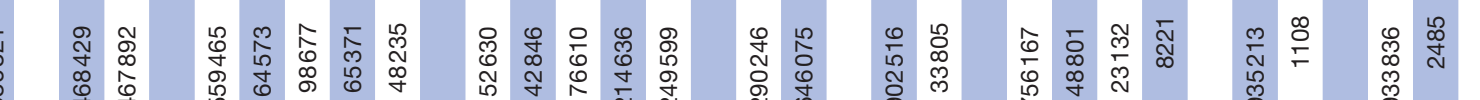

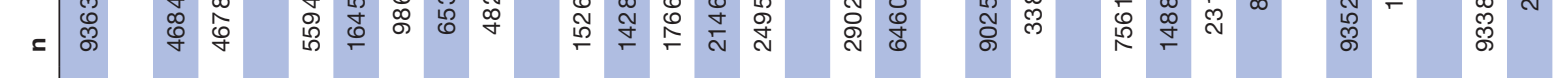

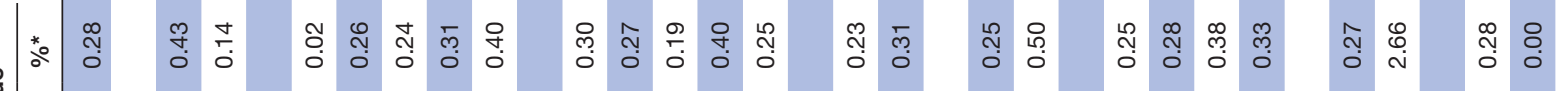
荡

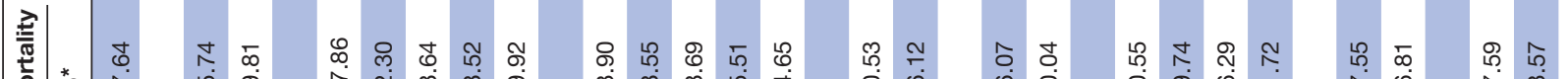

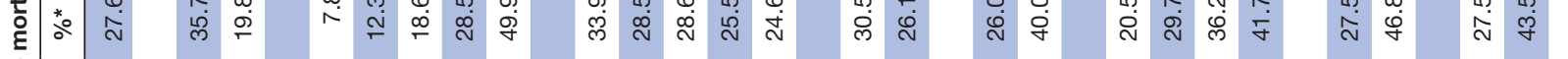

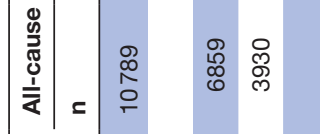
隽究

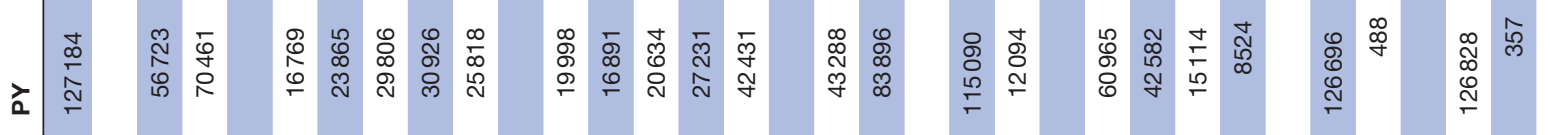

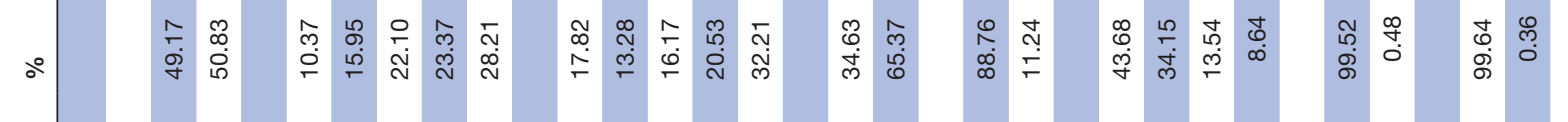

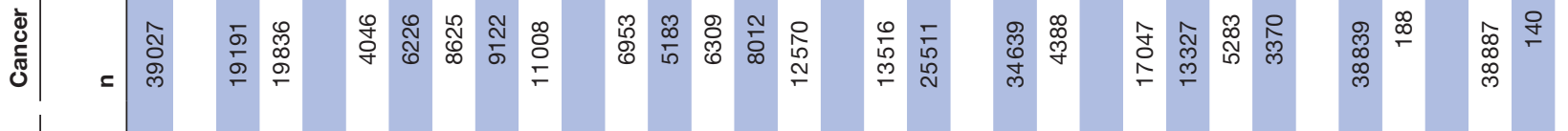

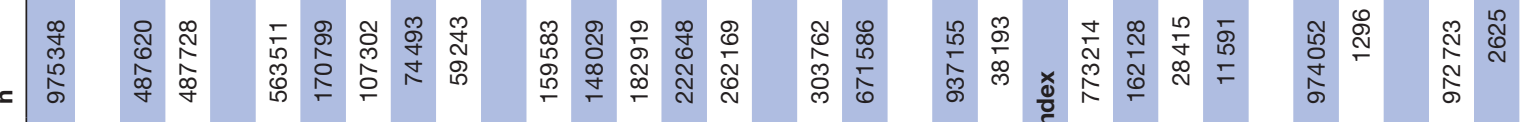

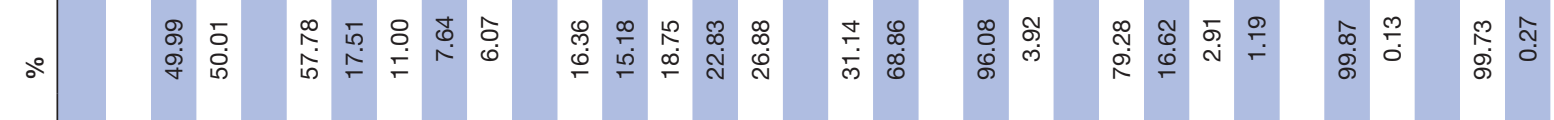




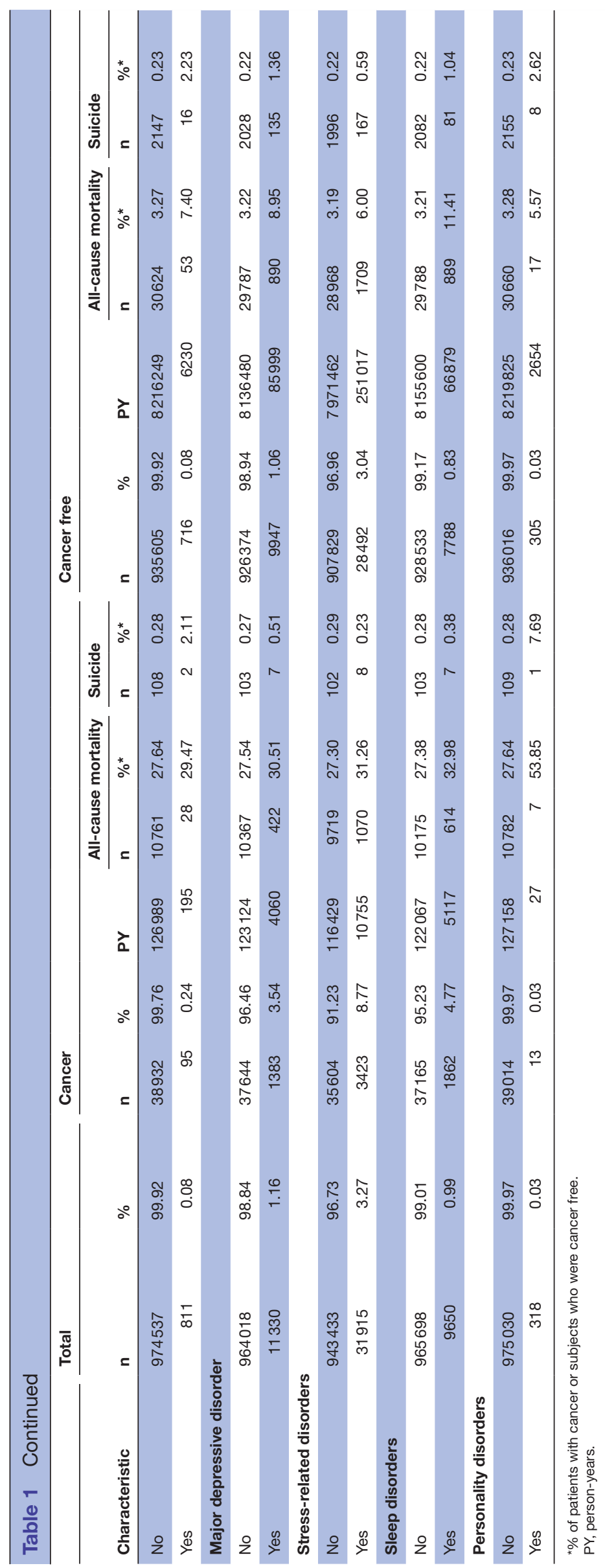

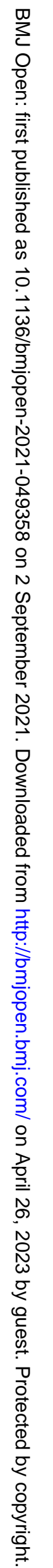




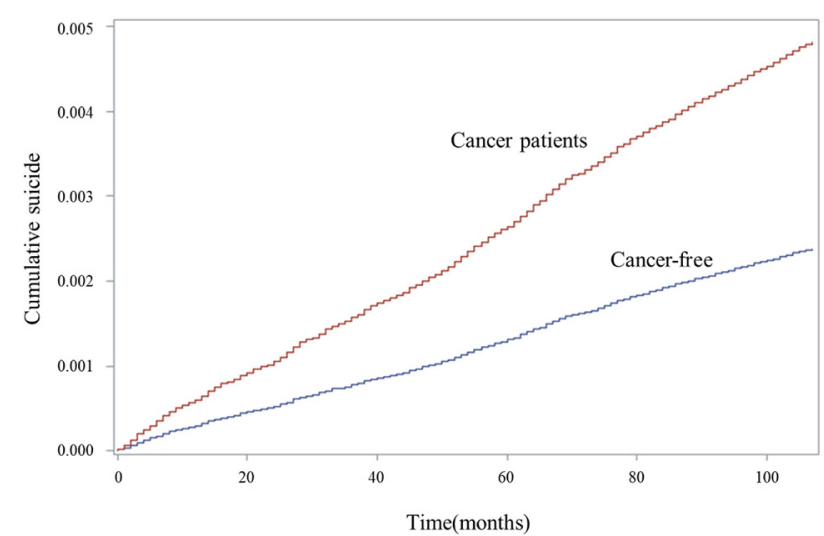

Figure 1 Cumulative suicide rates of patients with cancer versus cancer-free subjects.

(F31), major depressive disorder (F32-F33), anxiety and stress disorders (F40-F48), sleep disorders (F51, G47) and personality disorders (F6).

\section{Statistical analysis}

For this study, we determined the distributions of general characteristics by diagnosis of cancer. Additionally, relationships between household income level and suicide were analysed using time-to-event methods. The KaplanMeier method was used to generate curves of unadjusted mortality rates, which were compared using the log-rank test. To determine whether the suicide rate was higher among patients with cancer relative to the general population, multivariable analyses involving Cox proportional hazards models were conducted to calculate adjusted HRs plus $95 \%$ CIs as estimates of relative suicide rates. The proportionality assumption was tested by examining log curves (-log (survivor function)) versus time. A p value of $<0.05$ was considered to indicate statistical significance. All statistical analyses were conducted using the SAS software package (V.9.4; SAS Institute).

\section{Patient and public involvement}

Patients and the public were not involved in the design or planning of this study.

\section{RESULTS}

Table 1 presents the general characteristics of the study participants. Of the 975348 subjects, 39027 (4.0\%) received a diagnosis of cancer between 2005 and 2013, and a total of 110 suicides ( 82 men, 28 women) were identified among these subjects with cancer during a total of 127184 person-years. Of the 936321 cancer-free subjects with a total of 8222479 person-years, 2163 died by suicide during the study period. The suicide rate was 86 per 100.000 person-years in those with cancer compared with 26 in those without cancer. Using Kaplan-Meier survival curves of the unadjusted cumulative suicide rates among patients with cancer and cancer-free subjects (figure 1), a significantly higher risk of suicide was identified among the cancer group (log-rank, $\mathrm{p}<0.001)$.
Table 2 presents the results of a Cox proportional hazards analysis of the association between cancer diagnosis and suicide risk. Even after adjusting for factors related to suicide among patients with cancer, we observed an elevated relative risk of suicide (HR: 1.480, 95\% CI: 1.209 to 1.812 ). Notably, the relative suicide risk was significantly more elevated among male subjects (HR: 1.513, 95\% CI: 1.191 to 1.922$)$, compared with female subjects (HR: 1.320, 95\% CI: 0.895 to 1.947). Higher suicide rates were found to associate with male sex, older age, lower income, presence of a disability, higher Charlson Comorbidity Index and presence of psychiatric illness.

Figures 2-4 present the adjusted risks of suicide according to anatomical cancer site in both male and female subjects. Among men, the relative risk was increased substantially for patients with lip, oral cavity and pharyngeal (HR: $1.987,95 \%$ CI: 1.025 to 3.853 ), colon and rectal (HR: 1.906 ; $95 \%$ CI: 1.174 to 3.093 ), pancreatic (HR: 3.777 ; $95 \%$ CI: 1.211 to 11.784 ) and lung cancers (HR: 2.502; 95\% CI: 1.463 to 4.280 ), compared with the cancer-free group. Among women, the relative risk was substantially increased for patients with colon and rectal cancers (HR: 2.376, 95\% CI: 1.120 to 5.041 ).

\section{DISCUSSION}

\section{Summary}

In this population-based cohort study, we used data from the NHIS-NSC to investigate whether the risk of suicide was higher among patients with cancer than among the general population. We found that the suicide risk was indeed higher among those diagnosed with cancer during the study period, and that the risk of suicide varied according to the anatomical cancer site, as men diagnosed with lip, oral cavity and pharyngeal, colon and rectal, liver, pancreatic and lung cancers and women diagnosed with colon and rectal cancers had a significantly higher risk of suicide relative to the general population.

\section{Comparison with studies}

Our findings were consistent with those of other studies that examined the relationship between cancer diagnosis and suicide, in which the incidence rates of suicide among male and female patients with cancer were, respectively, 1.5 and 1.3 times higher than the rates in the general population after adjusting for factors associated with suicide. Similarly, in the USA, the suicide risk among patients with cancer is approximately twofold of the risk in the general population, ${ }^{13}$ and European studies have also observed increased suicide rates among patients with cancer. For example, Yousaf et $a l^{14}$ calculated SMRs of 1.7 and 1.4 for suicide among men and women, respectively, from a Danish cancer registry relative to the general Danish population. A similar study in Norway reported SMRs of 1.55 and 1.35. ${ }^{12}$ In Sweden, Björkenstam et al ${ }^{11}$ observed SMRs of 2.5 (men and women combined) for the period from 1965 to 1974 and 1.5 for the period from 


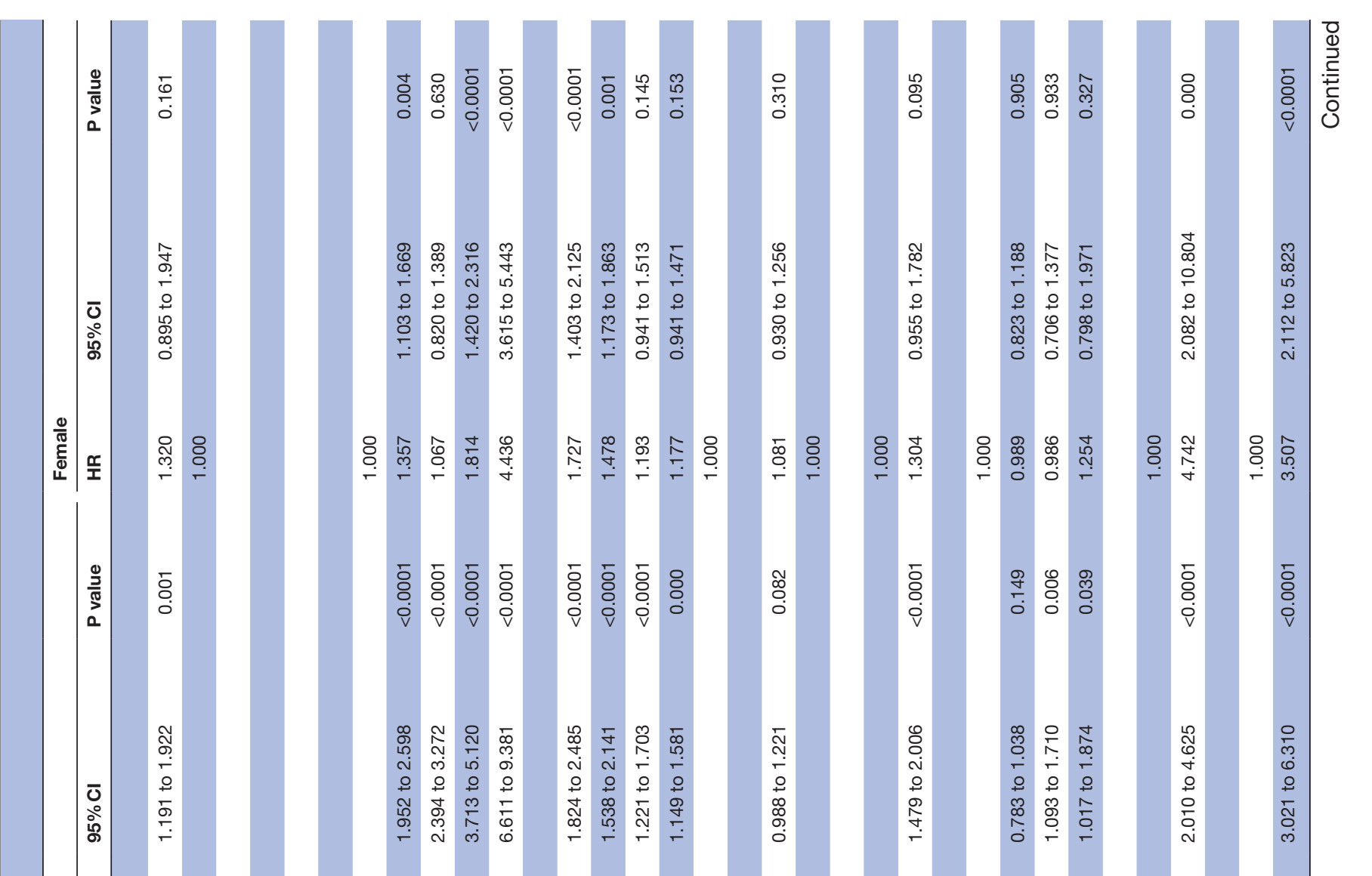

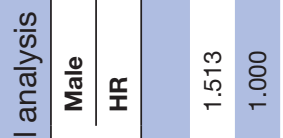

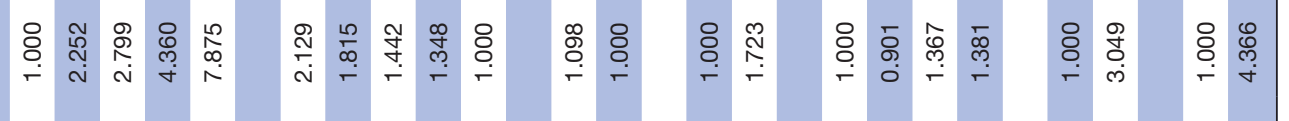
要

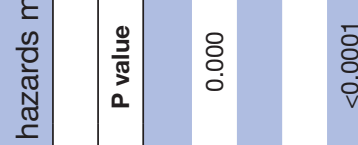

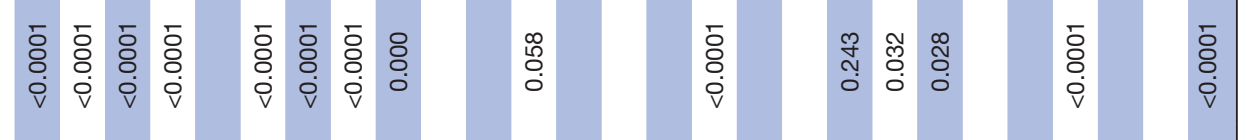

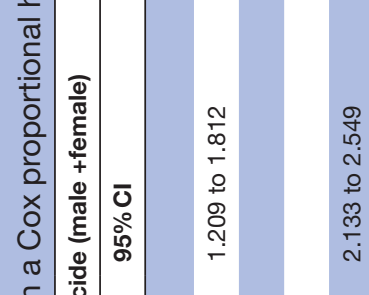
हิ

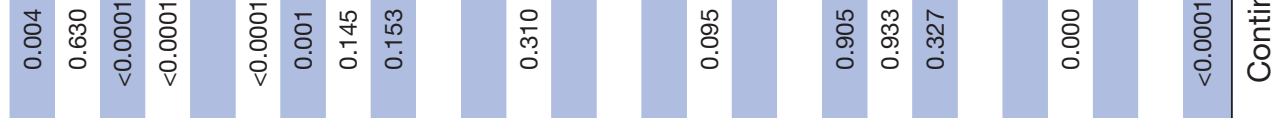

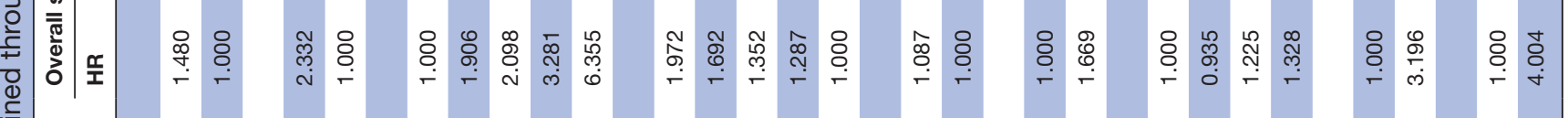




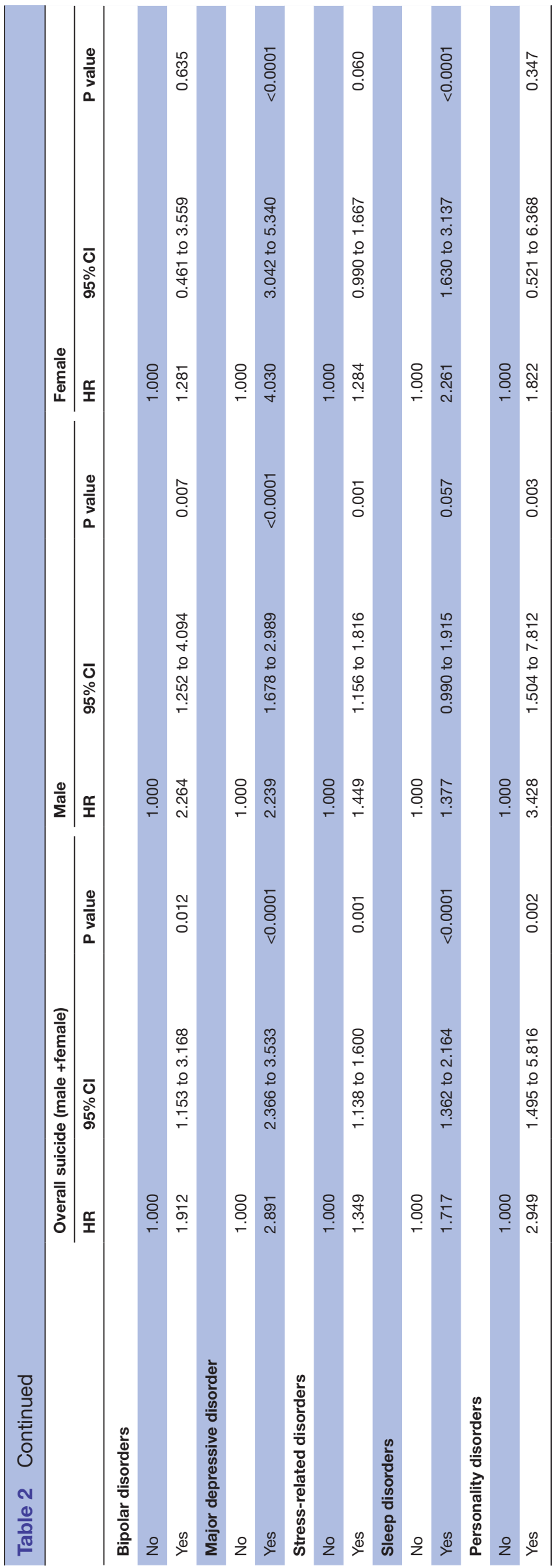

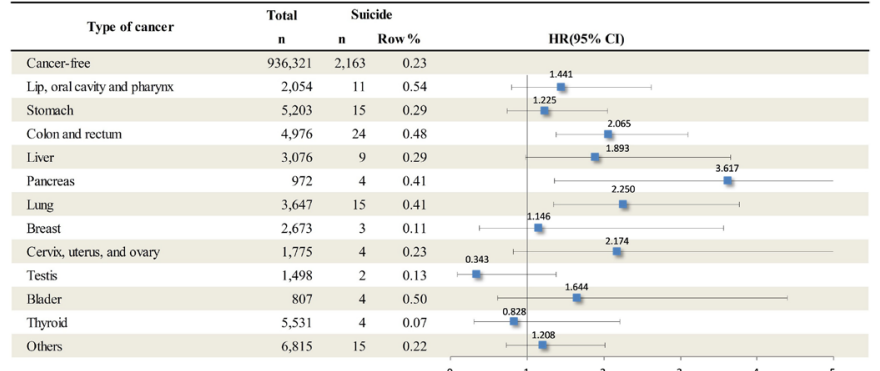

Figure 2 Adjusted risks of suicide by cancer type (all participants).

1985 to 1994. In Asia, a Korean study used cancer registry data to calculate SMRs of 2.05 among male patients and 1.87 among female patients for the period from 1993 to $2005 .{ }^{10}$

Several studies have found associations of cancers at certain anatomical sites with particularly elevated suicide rates. However, reports differ with regard to the anatomical sites associated with the greatest suicide risks. ${ }^{11-14}{ }^{16}$ In our study of patients in Korea, we found that the suicide risks were especially high among male patients with lip, oral cavity and pharyngeal, colon and rectal, liver, pancreatic, and lung cancers and among female patients with colon and rectal cancer, findings that were concordant with reports from Western countries. ${ }^{1-13}{ }^{26}$ Although the reasons underlying the associations of particular cancer types with increased suicide rates are unknown, patients with those cancers might struggle with grave prognoses. ${ }^{81416}$ This is corroborated by a finding that the suicide risk was higher among patients with cancers that conferred a poor prognosis (ie, 5-year relative survival of $<10 \%$ ), especially within the first year of diagnosis. Additionally, certain types of cancers, especially head and neck cancers, might have more profound effects on the quality of life and induce stronger degrees of anxiety or fear because of symbolic values, changes in appearance, or difficulties with speech, swallowing, and breathing. ${ }^{27}$ One study identified a $25 \%$ prevalence of depression among patients with lung cancer, ${ }^{28}$ and another study suggested that the lower quality of life among patients with lung cancer is related to emotional distress. ${ }^{29}$ Similarly, a high prevalence of depression has been observed among patients with head and neck cancer. ${ }^{30}$

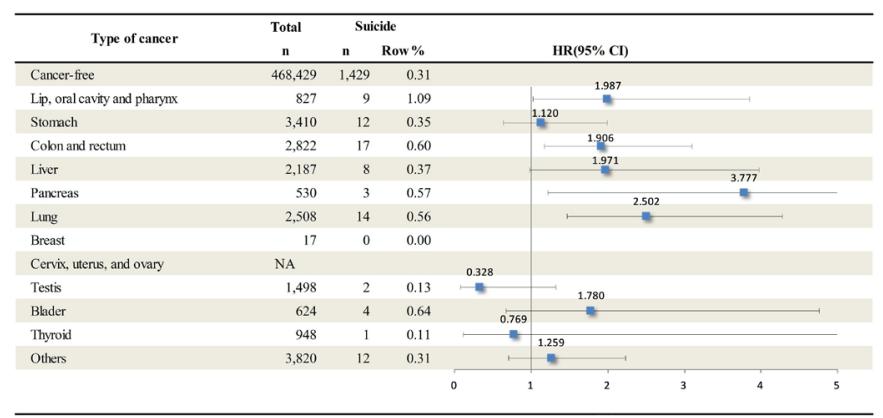

Figure 3 Adjusted risks of suicide by cancer type (men). 


\begin{tabular}{|c|c|c|c|c|c|c|c|c|}
\hline Type of cancer & $\begin{array}{l}\text { Total } \\
\end{array}$ & & & & & & & \\
\hline Cancer-fire & & & & & $\mathrm{HR}(95 \% \mathrm{CI})$ & & & \\
\hline $\begin{array}{l}\text { Cacererffec } \\
\text { Lip. oral caviv and plangnx }\end{array}$ & 467,892 & 734 & 0.16 & 0.660 & & & & \\
\hline $\begin{array}{l}\text { Lip, orac caviry and paryzx } \\
\text { Stumech }\end{array}$ & $\begin{array}{l}1,227 \\
1,793 \\
-1\end{array}$ & 3 & 0.17 & 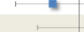 & 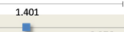 & & & \\
\hline Colon and rectum & 2,154 & 7 & 0.32 & & 2336 & & & - \\
\hline Liver & 889 & 1 & 0.11 & & 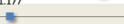 & & & \\
\hline Pancreas & 442 & 1 & 0.23 & 0.52 & & $=$ & & \\
\hline Lung & 1,139 & 1 & 0.09 & $=$ & & & & \\
\hline Breast & 2,656 & 3 & 0.11 & & 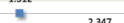 & & & \\
\hline Cervix, utens, and ovary & 1,775 & 4 & 0.23 & & 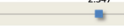 & & & - \\
\hline Testis & $\mathrm{NA}$ & & & & & & & \\
\hline Bhader & 183 & . & 0.00 & 0.910 & & & & \\
\hline Thyooid & 4,583 & 3 & 0.07 & 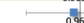 & & & & \\
\hline \multirow[t]{2}{*}{ Ohers } & 2.995 & 3 & 0.10 & 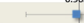 & & $\Rightarrow$ & & \\
\hline & & & & 0 & 2 & 3 & 4 & 5 \\
\hline
\end{tabular}

Figure 4 Adjusted risks of suicide by cancer type (women).

\section{Strengths and limitations}

The strengths of this study included the population-based design and acquisition of data from the NHIS-NSC, which is representative of the entire Korean population. In addition, this study featured a robust follow-up resulting from the use of unique personal identification numbers for Korean residents, which were linked to the national mortality database. Despite these strengths, our findings should be interpreted in light of the study's limitations. First, we were unable to examine the risk factors associated with specific cancer types because of the small number of suicides in each specific cancer group. Further study needs to examine the relationship between cancer and suicide according to cancer stage and cancer type by linking cancer registration data and claims data (not sample data) of all citizens. Second, as with other studies that employ administrative claims data, ${ }^{23}$ we were unable to identify some potential risk factors known to have important influences on suicide among patients with cancer, such as the family history of suicide attempts, history of suicide attempts and patients' histories of selfharm, which were unknown. Third, the use of administrative claims data is associated with particular issues. For example, a reliance on ICD-10 codes to determine comorbidity could lead to misclassification consequent to miscoding behaviours. Fourth, an inaccuracy on the ICD-10 codes for the diagnoses might have yielded some misclassifications due to the unavoidable characteristics of claims data, including miscoding of data by the original coder. Fifth, given the retrospective nature of this chart review study, we could not evaluate psychiatric symptoms after a cancer diagnosis, which are known to have an important influence on suicidal behaviours among patients with cancer, despite the availability of information regarding the history of psychiatric care. Sixth, our limited data set did not permit consideration of the influence of disease stage at diagnosis in our suicide risk analysis.

\section{CONCLUSION}

In our study of a cohort representative of the Korean population, patients with cancer were found to exhibit an increased risk of suicide, which varied according to the anatomical cancer site even after accounting for clinical comorbidities and psychiatric illness. These results provide further evidence of a relationship between cancer diagnosis and suicide. Further research into the suicide risks of patients with cancer should extend the range of concerns to include disease stage and clinical treatment.

Acknowledgements The authors appreciate the Yonsei University Institute of Health Services Research for its administrative support.

Contributors $Y C$ designed the study, analysed the data and wrote the draft. $Y C$ and $\mathrm{E}-\mathrm{CP}$ performed the literature review and interpretation for data analysis. All authors read and approved the manuscript.

Funding The authors have not declared a specific grant for this research from any funding agency in the public, commercial or not-for-profit sectors.

Competing interests None declared.

Patient consent for publication Not required.

Ethics approval This study adhered to the tenets of the Declaration of Helsinki. The study design was reviewed and approved by the ethical review board at the Graduate School of Public Health in Yonsei University (2-1040939-AB-N-01-2014239). Since our study used administrative cohort data, the requirement for informed consent was waived as the National Health Insurance Service-National Sample Cohort was constructed after anonymisation according to strict confidentiality guidelines.

Provenance and peer review Not commissioned; externally peer reviewed.

Data availability statement Data may be obtained from a third party and are not publicly available.

Supplemental material This content has been supplied by the author(s). It has not been vetted by BMJ Publishing Group Limited (BMJ) and may not have been peer-reviewed. Any opinions or recommendations discussed are solely those of the author(s) and are not endorsed by BMJ. BMJ disclaims all liability and responsibility arising from any reliance placed on the content. Where the content includes any translated material, BMJ does not warrant the accuracy and reliability of the translations (including but not limited to local regulations, clinical guidelines, terminology, drug names and drug dosages), and is not responsible for any error and/or omissions arising from translation and adaptation or otherwise.

Open access This is an open access article distributed in accordance with the Creative Commons Attribution Non Commercial (CC BY-NC 4.0) license, which permits others to distribute, remix, adapt, build upon this work non-commercially, and license their derivative works on different terms, provided the original work is properly cited, appropriate credit is given, any changes made indicated, and the use is non-commercial. See: http://creativecommons.org/licenses/by-nc/4.0/.

ORCID iDs

Young Choi http://orcid.org/0000-0002-8314-6130

Eun-Cheol Park http://orcid.org/0000-0002-2306-5398

\section{REFERENCES}

1 , Murray CJL, Barber RM, et al, GBD 2013 DALYs and HALE Collaborators. Global, regional, and national disability-adjusted life years (DALYs) for 306 diseases and injuries and healthy life expectancy (HALE) for 188 countries, 1990-2013: quantifying the epidemiological transition. Lancet 2015;386:2145-91.

2 OECD. Health at a glance 2015: OECD indicators. Paris: OECD Publishing, 2015.

3 Statistic Korea. Annual report on the cause of death statistics. Statistic Korea, 2015.

4 Cordova MJ, Andrykowski MA. Responses to cancer diagnosis and treatment: posttraumatic stress and posttraumatic growth. Semin Clin Neuropsychiatry 2003;8:286-96.

5 Zabora J, BrintzenhofeSzoc K, Curbow B, et al. The prevalence of psychological distress by cancer site. Psychooncology 2001;10:19-28.

6 Jie B, Qiu Y, Feng Z-Z, et al. Impact of disclosure of diagnosis and patient autonomy on quality of life and illness perceptions in Chinese patients with liver cancer. Psychooncology 2016;25:927-32.

7 Reiche EMV, Nunes SOV, Morimoto HK. Stress, depression, the immune system, and cancer. Lancet Oncol 2004;5:617-25.

8 Fang F, Fall K, Mittleman MA, et al. Suicide and cardiovascular death after a cancer diagnosis. N Engl J Med 2012;366:1310-8. 
9 Baade PD, Fritschi L, Eakin EG. Non-Cancer mortality among people diagnosed with cancer (Australia). Cancer Causes Control 2006;17:287-97.

10 Ahn E, Shin DW, Cho S-I, et al. Suicide rates and risk factors among Korean cancer patients, 1993-2005. Cancer Epidemiol Biomarkers Prev 2010;19:2097-105.

11 Björkenstam C, Edberg A, Ayoubi S, et al. Are cancer patients at higher suicide risk than the general population? A nationwide register study in Sweden from 1965 to 1999. Scand J Public Health 2005;33:208-14.

12 Hem E, Loge JH, Haldorsen T, et al. Suicide risk in cancer patients from 1960 to 1999. J Clin Oncol 2004;22:4209-16.

13 Misono S, Weiss NS, Fann JR, et al. Incidence of suicide in persons with cancer. J Clin Oncol 2008;26:4731-8.

14 Yousaf U, Christensen M-L, Engholm G, et al. Suicides among Danish cancer patients 1971-1999. Br J Cancer 2005;92:995-1000.

15 Louhivuori KA, Hakama M. Risk of suicide among cancer patients. Am J Epidemiol 1979;109:59-65.

16 Robinson D, Renshaw C, Okello C, et al. Suicide in cancer patients in South East England from 1996 to 2005: a population-based study. Br J Cancer 2009;101:198-201.

17 Robson A, Scrutton F, Wilkinson L, et al. The risk of suicide in cancer patients: a review of the literature. Psychooncology 2010;19:1250-8.

18 Innos K, Rahu K, Rahu M, et al. Suicides among cancer patients in Estonia: a population-based study. Eur J Cancer 2003;39:2223-8.

19 Ahn MH, Park S, Lee HB, et al. Suicide in cancer patients within the first year of diagnosis. Psychooncology 2015;24:601-7.

20 Kendal WS. Suicide and cancer: a gender-comparative study. Ann Oncol 2007:18:381-7.
21 Lu D, Fall K, Sparén P, et al. Suicide and suicide attempt after a cancer diagnosis among young individuals. Ann Oncol 2013;24:3112-7.

22 Guan NC, Termorshuizen F, Laan W, et al. Cancer mortality in patients with psychiatric diagnoses: a higher hazard of cancer death does not lead to a higher cumulative risk of dying from cancer. Soc Psychiatry Psychiatr Epidemiol 2013;48:1289-95.

23 Choi Y. The effect of income level on all-cause mortality and suicide among patients using antidepressants: a population-based cohort study. Psychiatry Res 2021;299:113838.

24 Lee J, Lee JS, Park S-H, et al. Cohort profile: the National health insurance Service-National sample cohort (NHIS-NSC), South Korea. Int J Epidemiol 2016;95:dyv319.

25 Quan H, Sundararajan V, Halfon P, et al. Coding algorithms for defining comorbidities in ICD-9-CM and ICD-10 administrative data. Med Care 2005;43:1130-9.

26 Dormer NRC, McCaul KA, Kristjanson LJ. Risk of suicide in cancer patients in Western Australia, 1981-2002. Med J Aust 2008;188:140-3.

27 Semple C, Parahoo K, Norman A, et al. Psychosocial interventions for patients with head and neck cancer. Cochrane Database Syst Rev 2013;8.

28 Carlsen K, Jensen AB, Jacobsen E, et al. Psychosocial aspects of lung cancer. Lung Cancer 2005;47:293-300.

29 Sarna L, Padilla G, Holmes C, et al. Quality of life of long-term survivors of non-small-cell lung cancer. J Clin Oncol 2002;20:2920-9.

30 Duffy SA, Ronis DL, Valenstein M, et al. Depressive symptoms, smoking, drinking, and quality of life among head and neck cancer patients. Psychosomatics 2007;48:142-8. 